\title{
Climate change and adaptation strategies: a study of agriculture and livelihood adaptation by farmers in Bardiya District, Nepal
}

\author{
Dr. Prakash Upadhyay \\ Tribhuvan University, Prithvi Narayan Campus, Pokhara, Nepal
}

Correspondence: Dr. Prakash Upadhyay, Associate Professor of Anthropology, Tribhuvan University, Prithvi Narayan Campus, Pokhara, Nepal,Email prak-socio@hotmail.com

Received: February 15, 2019| Published: March 27, 2019

Copyright@ 2019 Upadhyay et al. This is an open access article distributed under the terms of the Creative Commons Attribution License, which permits unrestricted use, distribution, and reproduction in any medium, provided the original author and source are credited.

\begin{abstract}
Climate change impact is perceived to contribute in raising temperature, agro-bio diversity extinction, agro-production decline and emergence of vector born diseases that created negative impact on agriculture and livelihood. Without any external support, accentuating collective experiences based on cultural framing, the local farmers' fashioned integrated adaptation strategies, updated the indigenous practices to agricultural diversification by altering crop cultivation period, adopting alternative crops, hybrid livestock, dairy co-operative and micro credit services. The performative integrated adaptation practices visualized on indigenous environmental knowledge, cultural valuation and responses mediated farmer's engagements with natural phenomenon and framed the ways they observed, understood, experienced and cope-up to climatic variations hence confirming that agriculture and livelihood adaptation is obviously a socio-culturaltechnical process.
\end{abstract}

Keywords: Bio-diversity, compulsive adaptation, culture of prediction, food security

\section{Introduction}

Global climate change is deviation in climatic conditions accredited directly or indirectly to human actions that alter the composition of global atmosphere and which are in addition to natural climate variability observed over time periods. Anthropogenic global climate change, as distinct from natural climate variability denotes not only variation in temperature but also rainfall, humidity, cloudiness, and winds. NAPA (2010) affirms that geophysical and socio-economic condition, fragile ecosystem and global warming have kept Nepal continually in the threat of destruction in relation to diverse biodiversity, ecology and infrastructure. ${ }^{1}$ The consistent warming and rise in maximum temperature is at an annual rate of $0.04-0.06^{\circ} \mathrm{C}$. Kates ${ }^{2}$ argues that due to its limited capacity to cope with hazards associated with climate change, Nepal remains more susceptible to climate change impact. For Aase et al. ${ }^{3}$ climate change and variability have stronger impact on subsistence farmer reliant on rain-fed agriculture. It affects agriculture with direct impact on food production and livelihood attributable to natural climate cycle and human activities as seen in the context of Terai region of Nepal. The fertile Gangetic plain makes the Terai ( $23 \%$ of Nepal's total fertile land area) with surplus agricultural production to supply the less productive hill/mountain areas. However, in the last many decades Terai has seen worst climate change with severe drought, extreme and recurring flood, landslides, etc. ${ }^{4}$ Manandhar et al. ${ }^{5}$ corroborate that because of dependence on natural resources and subsistence agricultural production, climate change impact on Terai people is severe. Eastern Terai rural farmers have observed delayed more intense and frequent flooding season, severe cold waves and resulting extinction of agro-bio diversity and emergence of vector-borne diseases that have forced new adaptation methods to be adopted by them in agriculture and livelihood. Aase et al. ${ }^{3}$ affirm that the lack of rain in 2009 had reduced the summer crop production by up to (30-50) in Terai.

Backwardness, poverty and high level of dependency on subsistence agriculture have limited the climate change coping capacity of a large bulk of local farmers in Terai. From climate science perspective, localizing is the process of downscaling from global climate models to specific places, accommodating local risk perceptions, experiences, vulnerability, adaptation and the inability of top-down methods to address local farmer's concerns- climate change impact on their food production and livelihood security. Yet, localizing and accommodating risk concerns, experiences and climate change adaptation strategies at rural agricultural setting, biodiversity and livelihood has been neither well documented and valued nor well promoted by government and non-governmental agencies in Nepal. Given this, the objective of this paper is to appraise how climate change has been experienced by the rural farmers of Terai, vulnerabilities faced and the strategies adapted at local level to minimize climate change impact on agriculture and livelihood.

The study site Jamuni is a part of Badhaiyataal Gaupalika (Village Council administrative unit) of Bardiya district of outer Terai in midwestern Nepal. Bardiya was a part of Nepal before it was ceded to the British East India Company under Sugauli Treaty. In the mid nineteenth century, Bardiya was returned to Nepal. Before 1950, Bardiya was covered with dense forest sparsely populated with indigenous Tharu population. The district has mostly lower tropical temperature with summer temperature 40 degree Celsius. In the last few decades due to climate change, the yearly maximum average temperature has varied in the district with increasing pattern that 
has added hardships in livelihood. ${ }^{6}$ Poor infrastructure, unplanned urbanization, raising temperature, drought and flood has seriously influenced agriculture and livelihood of the farmers in this district. In the study site Jamuni, flood victim hill people from different regions of Nepal were re-settled under the Resettlement Project (1970-71). A major bulk of forest has diminished after the Resettlement Project.

With a population of 11,539 (Male 5,073/Female 6,466) in 2,601 households with average household size 4.44, and literacy rate $61.4 \%$, agriculture is the main occupation of 1925 (74\%) households in Jamuni. ${ }^{7}$ Guided by the philosophical principles of Positivist and Interpretivist tradition, which Chhetri ${ }^{8}$ terms as "combination of anthropological and survey method", both qualitative and quantitative approaches were used in this study. The field study was conducted in a rigorous field study period during March 21-April 24, 2018. Using the quantitative survey method, at first, households listing were done to identify eligible respondents (household heads above 60 years of age) from mainly rain-fed agriculture dependent households and 620 household heads (386 male and 234 female) were found eligible. From these, as per purposive random sampling, 150 household heads ( 85 male and 65 female), one each from 150 households were selected for the study on the ground that as elderly farmers they were the key decision makers in household activities and possess good experiences of climate change impacts. Their average educational qualification was $9^{\text {th }}$ grade and had multiethnic composition comprising resettled hill origin Pahadiya (Chhetri 24\%, Brahmin 18\%, ethnic or Janajati 14\%, low caste Dalit 15\%), Terai origin Madhesi (19\%), and indigenous Tharu (10\%). Pahadiya Brahmin-Chhetri, Dalit and Janajati possess an average landholding of 1 Bigha (equivalent to $6772.63 \mathrm{~m}^{2}$ ) per household and Madhesi and Tharu 0.4 Bigha. This disparity in landholding is due to the Resettlement Project scheme that had allocated 3 Bigha of land to each flood victim hill origin family. Survey method was used to collect information on the impact of climate change on biodiversity, status of crop production, livelihood and adaptation strategies which supplemented the qualitative ethnographic information collected through interviews, observations and case studies on personal experiences, valuation and responses on climate change.

\section{Conceptual Framework}

Eisenack and Stecker ${ }^{9}$ framework on climate change adaptation conceptualized adaptation to climate change as actions referring only to human systems, individuals and collective actors (farmers). Action requires actors, relations to adaptations and an intention. Adaptations need the use of resources as means to achieve the intended ends with hurdles to implementation. As processes within entities and systems or adjustments made by human systems, adaptation is a response to environmental stimuli that affect, entities, or systems viz. human systems and collective actors. Farmer's adaptation needs the use of resources as mediums to achieve the intended ends. A stimulus is an alteration in biophysical e.g. rainfall variables or abrupt events in the earth's ecosystem and germane for adaptation when it influences an exposure unit including social, technical or non-human systems that rely on climatic conditions, and are exposed to stimuli.

Exposure units affected by climate change and adaptation and receptors of adaptation can be both actors and biophysical units, while operators are actors. The individual or collective actor (farmer) that exercises the response is an operator (a social entity) which tries to achieve intended ends linked with other actors, social or non-human systems. The ends are ultimately targeted at impacts. The actor or system that is the target of purpose (adaptation) is the receptor viz. biophysical entities, famer's crop and social systems like household and livelihood. In the course of action, adaptation strategies is sustained by knowledge, valuation, responses, local cultural meanings and values to interpretations of climate as claimed by White. ${ }^{10}$

\section{Impact of Climate Change on Biodiversity, Agriculture and Livelihood}

Deforestation for the settlement of hill origin people, construction of houses and population rise resulted in severe ecological unbalance in Jamuni, hence climatic change and its impacts were experienced severely that forced the farmers attuned to adaptation. The impact of climate change was experienced in decreasing rainfall, extinction of various species of vegetation, alteration in the nature of weather, humidity and temperature. The situational pressure of climate change influenced the customary ways of living; livelihood efforts were being harder, perceived and experienced in daily life. Unseasonal, erratic and decreasing rainfall, rising temperature resulting in summer drought, and oddly low temperature and cold waves during winter, was affecting agriculture and biodiversity. Farmers were in constant trauma of water scarcity. Water sources were drying up with reduction in underground and river water level and wet-land was becoming arid. Natural ecosystem and biodiversities were affected with disdainful impact on many local flora-fauna species-Sal tree (Shorea robusta), Jute, Cotton, Sugarcane, Bees and Cranes etc. Many local species e.g. bees, eagles, cranes have disappeared.

Farmers $(95 \%)$ stated that frequency of summer storm had increased causing damage to shelters and crops. Conventional paddy and wheat were replaced by new hybrid species. The significant reduction in jute and sugarcane production caused economic losses and shifting of agricultural pattern. Cotton was the main cash crop during 1970s, but now its cultivation has been abandoned owing to deteriorating soil quality. The production of many crops has been persistently in declining trend. In the last forty years despite the decline in mustard, maize and lentil production, paddy production has increased due to the use of advanced fertilizer. Climate change triggered altering seasonal rainfall caused variation in agricultural production with difficulties in plantation and harvesting that threatened food security and livelihood requiring the farmers to work harder to fulfill their food needs. About 98\% farmers claimed that rising temperature, a result of deforestation and decreasing rainfall, had shortened crop maturation and maturation period of seed germination. Appearance of new pests on crops, decline in routine crops obliged the farmers to consume pesticides in crops and vegetables grown with the undue use of chemical fertilizer, pesticides and insecticides. The insects and pests were not killed despite the use of insecticides. The taste of cucumber and cauliflower was changed forever.

Frequent droughts had an adverse effect on the growth of palatable grass species. Slower regeneration of fodder species, scarcity of pasture land forced the farmers to alter traditional livestock rearing pattern; traditional livestock keeping for livelihood had decreased notably. Occurrence of thick fog in the region also obligated farmers to abandon livestock grazing. Extreme cold winter and hot summer affected milk and meat production. Most farmers (89\%)=reported decreasing income from traditional livestock. Not only there is the scarcity of grazing land, in the last 15 years, farmers were incessantly experiencing new diseases and death of livestock owing to increasing temperature and rising number of flies/mosquitoes. However, there was no any support from government's agriculture support centre. 
Cook $^{11}$ has illustrated that while climate change is not solely destructive, the negative impact of global warming on agriculture and human health are disturbing. Raising temperature and excessive use of chemical fertilizers/pesticides on crops led to serious impact on farmers' health in Jamuni. Tropical and viral diseases were frequent in all seasons. Farmers noticed increased flies, mosquitoes, bugs, termites and experienced multiple health problems-increasing sickness of aged and infants, gastroenteritis, increase in vector-borne parasitic diseases-malaria, Japanese encephalitis, viral influenza, allergies, skin rashes, and menstrual ailments. Food-borne diseases were escalating as a result of rising temperature. Water-borne diseases were increasing with extra demands of diminished water supplies, escalating the risk of contaminated (Arsenic mixed) boring water reaching the public. One case woman respondent of hill origin shares her experience:

The upshot of climate change resulting in raising temperature has been severe on human and animal health. Beforehand there were no severe problems of communicable diseases even though there were no toilets but now each home has its toilet and practice of open defecation is also reduced. It was not necessary to use mosquito nets previously, but now I use mosquito nets due to the surprise appearance of mosquito not only in night but during day time also. I am astounded and worried on frequent outbreak of vector and water borne diseases, health expenses are mounting awfully. Explosion of new diseases are the result of changing Mausam (climate).

\section{Adaptation in Agriculture and Livelihood as Response to Climate Change}

Indigenous communities in rural Nepal have been using indigenous knowledge and practices to adapt to both the climatic and non-climatic changes. ${ }^{12}$ Local people globally, have shown the adaptation in cropproduction by mix-cropping system, farmers use breeding livestock for greater tolerance and productivity, use their indigenous knowledge for climate variability and mode of production. ${ }^{13}$ Ajani et al. ${ }^{14}$ describe indigenous adaptation strategies practiced in sub-Saharan Africa and the benefits of integrating indigenous knowledge into formal climate change adaptation strategies. Exploring the challenges and opportunities of integrating, synergizing, and complementing indigenous practices with modern scientific knowledge/technologies, Karki and Adhikari ${ }^{15}$ argue that integrating indigenous with modern knowledge for sustainable conservation and management of ecosystems has been largely successful in Nepal.

Adopting an integrated approach-indigenous and modern, farmers in Jamuni followed two steps--first perceived climate change impact and then decided to adopt particular measure. The premises upon which they made basic adaptation decisions were multiple that emerged from direct environmental stimuli, socio-cultural locations, and ideological norms. Using their knowledge, valuation was given to what they know in terms of shared meanings and perception on climatic changes and responded individually and collectively. About $75 \%$ farmers experimented, used indigenous knowledge, methods and experiences, improved conventional techniques and adopted integrated methods to tackle climate change menace. They developed adaptation capacity with changes under own initiative with limited monetary and technical methods. Though as rural farmers, they had meager knowledge on adaptation techniques of climate change, but had perceived, experienced effects on agriculture and livelihood and were striving to adjust accordingly. One Madhesi farmer respondent recounts:

Two different dimensions of the use of indigenous knowledge are crucial -the content of indigenous knowledge in terms of strategies, tools, and techniques for responding; and the processes through which this knowledge is transmitted and put into action including social learning, knowledge sharing, and responses in an updated way. There is close link between indigenous and updated scientific practice (the way we people observe, interpret, and build knowledge from our interactions with the environment) and our cultures in which it is embedded, as which is inseparable. The use of Adivasi (indigenous) and updated Adhunik (modern) practices are the part of my ekikrit (integrated) Rananiti (strategy) to adapt climate change impact on agriculture and livelihood.

For the farmers, survival was the concern, adaptation as interaction with nature reproduced through practices prioritized that were socially constituted and culturally meaningful/pragmatic and were constructed through compulsive adaptation practices for sustaining agro-production and livestock for greater productivity. Farmers' knowledge and skills of their environment and its relationships with social systems formed key elements of their updated and modified adaptive culture, capacity and identity to cope climate change impacts. Understanding of the interactions of culture and climate, and in meticulous the role of perceptions, knowledge, and values as elements of interactions, brought farmers to focus on adaptive responses. Technologies and environmental knowledge and climate adaptations enacted by Jamuni farmers were based on what Richards ${ }^{16}$ termed as performative knowledge, a competence inbuilt in farmers' timehonored and location-specific experience embedded with modernity rather than preset in abstract principles.

Farmer's responses to climate variability consisted of iterative succession of improvised strategic adjustments. Based on their expectations of what the climate might be, farmers proceed to carry out agricultural practices. Moderately, they get their demeanors by analyzing the environment during the weeks and months that lead up to the beginning of the rains, and continue to do so until the feasible planting time, a process that depend on a mix of sensory insight, cumulative experience, learned skills and media information. During normal rainfall, farmers find easy following cropping schedule pursuing their traditional cropping calendar as: Paddy $\rightarrow$ Wheat $\rightarrow$ Fallow, Paddy $\rightarrow$ Lentil $\rightarrow$ Fallow, Paddy $\rightarrow \mathrm{Pea} \rightarrow$ Fallow. However, delays in monsoon in the last four decades compelled the farmers to change the cropping pattern and crop maturity period due to which crops planting and harvesting has been pushed back by more than one and half month that altered the normal cropping calendar and forced the farmers to adapt new cropping sequence viz. Paddy $\rightarrow$ Wheat (Table 1).

Table I Cropping Calendar during Delayed Rainfall

\begin{tabular}{llllll}
\hline $\begin{array}{l}\text { Months/crops } \\
\text { Paddy }\end{array}$ & May & June & August & November & January \\
Wheat & ${ }^{\text {st }} W k(S S)$ & $2^{\text {nd }} W k(T)$ & $2^{\text {nd }} / 3^{\text {rd }} W k(H)$ & \\
\hline
\end{tabular}

Source: Field Survey, 2018, *Wk:Week, SS: Seed Sowing, T:Transplanting, H: Harvesting 
Delayed, short rainy season and short crop growing season resulted in the disturbance of entire agricultural cycle including paddy transplantation. Late harvesting of paddy has hampered the cultivation season of wheat and mustard. Previously maize was grown in April but now it is grown in November-December. Irregular rainfall pattern has hindered the growth of long-season local varieties of crops; hence they were experimenting with hybrid varieties viz. hybrid paddy. Climate friendly agricultural practices-adoption of new short season hybrid crop varieties, altering planting and harvesting time was prioritized. The activities related to agro-forestry such as plantation of hybrid fodder species and grass species was becoming popular. All these practices of multiple adaptations were carried out on the basis of experiences and local skills. Some other strategies that served as an important form of indemnity against rainfall variability were increasing agricultural diversification by planting crops that are drought tolerant and/or resistant to temperature stresses, making efficient use of available water sources, and growing a variety of crops, hence reducing the risk of complete crop failure since different crops are affected differently by climate changes. In order to avert crop failure from unusual rains and recurrent droughts, pursuing multiple adaptation strategies, the farmers sought alternatives--cultivation of off-season/alternative crop varieties. Some farmers had discarded paddy tillage and were cultivating cauliflower, cabbage, chili, tomato and cucumber as alternative to paddy while growing sunflower, banana as cash crops (Table 2).

Table 2 Integrated Adaptation Strategies per Household

\begin{tabular}{ll}
\hline Multiple Strategies & Adopted Percent \\
\hline Change in crops varieties/growing alternative crops & 75 \\
Change in planting \& harvesting time & 73.33 \\
Seed savers, conserving crop diversity, seed banks & 77 \\
Artificial irrigation (underground boring water) & 80 \\
Use of organic (compost) manure & 53.33 \\
Use of NPK fertilizer and pesticides & 57 \\
Economic diversification & 31 \\
Improved breeds of livestock, apiculture & 35 \\
Livestock insurance & 20.66 \\
Use of biogas, improved stove & 26 \\
\hline
\end{tabular}

Source: Field Survey, 2018

Seed banks and seed saving were widely popular. Farmers had prepared seedlings of different crops and sharing them with members of self-help groups of the village. They were conserving crop diversity with participatory seed selection in crops such as paddy, wheat etc. Their seed bank was thriving for preserving the seeds of different crops via community seed banks. Along with the use of organic manure (dung), the use of NPK (Nitrogen Prosperous Potassium) fertilizer was escalating as a compulsion. Such adaptations aimed at increasing productivity deals with existing climatic conditions drawing on farmers' knowledge and agricultural experience. The economic diversification in families included foreign employment, occupational shift towards business or migrating to other places for better opportunities.

Despite many drawbacks, one of the benefits of changing climate was the introduction of improved breeds of livestock. As an adaptation strategy, farmers had shifted towards improved breeds of hybrid livestock rather than local breeds and the practice of keeping many unproductive livestock had reduced. With few numbers of hybrid livestock, there is no need of more grazing land; hence stall feeding practice was given valuation. Livestock insurance was also popular. After the establishment of dairy cooperatives, milk selling had emerged as a new venture with the collected milk sold to the dairies. The community dairy producer group made a profit of Nepali currency Rs. 60,000 in 2017 by training the farmers in palatable grass seeds, and medicines for livestock. The introduction of agro-forestry initiative was an experiment to adapt to new environment. Farmers had group approach to claim the degraded land at the bank of Manakhola River for fodder promotion, income generation activities through cash crops and community plantation via adoption of community forest approach.

By recognizing and acknowledging the power of change trajectory, farmers' saw alternatives that aided them in their work of understanding how the world works. Local experiences based saving and micro credit initiatives had thrived targeting to save the farmers from expensive interest rates of local landlords. Farmers invested the credit facilities in small enterprises-vegetable farming, goat rising, poultry and managing agro-input (seed, tools, fertilizer, pesticides) etc. Modern Apiculture was becoming popular. These initiatives were supportive to minimize the risks of crop failure and extreme weather shocks. With diminishing forest resources, farmers gave valuation to indigenously prepared Briquette (dried mixture of husk/dung) as fuel. Alternative technologies such as Biogas, Solar Housing System and improved stoves were used to cope with thinning forest products. The promotion of private agro-forestry was rising. About $40 \%$ farmers had preferred fast growing trees like Eucalyptus, Epil-Epil, Bamboo, Mulberry etc for firewood and animal fodders. Planting new varieties of grass and fodder (Napier grass, Lemongrass and Epil-Epil) in private land was becoming popular.

Farmers were using local organic substances like mustard oil, organic Neem (Azadirachta indica) extract and many local species of plants to control mosquitoes and were motivated to fill the ditches and clean their surroundings. Local NGOs were conducting awareness programs on health to reduce the effects of diseases by creating awareness on curtailing chemical fertilizer/pesticide uses on crops. Broadly, climate change as an issue has played an increasing role in reinforcing and shifting farmers positions allowing them better understanding and adaptation to changing climate in order to manage it in better ways for their and community benefit.

\section{Indigenous Adaptation, Collectivism and Social Solidarity}

Anthropologists have studied the underlying tension in weather forecast dissemination between scientific forecasts and local climate 
prediction practices. ${ }^{17,18}$ While most of them focus on the differences between traditional environmental knowledge and scientific knowledge, some research shows important points of congruence. ${ }^{19}$ Nabhan ${ }^{20}$ describes how indigenous inhabitants of the arid American Southwest and of northwestern Mexico note with delight that after rare rainstorms, the desert smells like rain. Body's senses and mental models are chief avenues through which farmers get to know their local weather in its particular manifestations e.g. rain, hail, snow, wind, and temperature. Orlove et al. ${ }^{21}$ exemplify that Ugandan farmers might see clouds in the sky and, based on their color and shape, know whether it will rain; they may feel the wind and, based on its direction or strength, recognize whether it will bring rain or chase it away; they may hear thunder and see lightning flashes on the horizon and, based on their orientation, predict whether the storm will head their way; they may feel heat at night, and, based on its intensity and the time of year, discern whether planting time is approaching.

Tschakert ${ }^{22}$ (2007) exemplifies that in many parts of the world, trees, wind, and birds are the subjects of attentive scrutiny by local farmers who rely on them to predict seasonal rainfall. As indigenous culture of prediction ingrained in environmental anthropology, farmers in Jamuni were using the indigenous environmental knowledge on rain forecasting. Amid unusual rainfall pattern, the Jamuni farmers comprehend the rainfall pattern by using their visual and sensory perceptions, mental models, indigenous environmental knowledge and experiences concurring to Strauss and Orlove' ${ }^{23}$ argument that visual and sensory perceptions are key elements of the folk epistemology of climate. In indigenous Tharu community of Jamuni, based on collective experience and cultural framing based on folk narratives of climate change (passed on between generations), the indigenous knowledge of rain forecasting has proved effective in comprehending the rainfall pattern. Elderly Tharu farmers predict rainfall when the house sparrows play in the dust on the ground and when black ants come out from the cleft carrying their eggs and seeking elevated place. Likewise, when numerous fire-flies revolve around trees at night Tharu farmers predict that there is a possibility of rain. Farmers believe that when the eastern wind stops blowing in the month of August and western wind start to gust, this wind will bring rain. Ribbit of frogs signify that there will be a heavy rainfall. If there is eastern wind in the month of November-December, clouds may form but there will be no rain. Rain may occur when the evening sky appears red in the east. It is a belief that a distance smoky halo around the sun will bring early rain and vice-versa. Cattle will be contented and lope when it is about to rain. Formation of elephant trunk shape cloud below the rainbow is an indication of heavy rain in near future. The predictions of these rain prophets urge the farmers for agricultural preparation in the anticipation of rainfall which is an indigenous adaptation of its kind against the changing climate. Pahadiya and Madhesi farmers have also emulated this culture of rain prediction.

One Tharu farmer respondent revealed a weird/bizarre ritual performed during summer drought.

Our women perform weird/bizarre. They plough their house yard reversely at midnight naked singing songs to appease the rain god. No males are allowed to observe the dance and if someone is caught, he is punished and penalized to offer foodstuffs to the Devta (god). This ritual brings our people together and reaffirms our faith in female preeminence, the collectivism; promote social solidarity that helps us cope to the drought. For me climate change is the worst of the nature but best for our community's solidarity.
Concurring to fetishism, an interesting but conventional approach to soil fertility conservation is popular among Pahadiya and Madhesi farmers in Jamuni. It is the belief that if the Bhumi Devi (earth goddess) is appeased through consultations and ritual Puja (worship), mother earth (symbolic to female fertility) would yield bumper harvests. Based on indigenous epistemologies, seeing and knowing local youths were learning and gave valuation to different practices by passionately watching and practicing with elderly people. Elderly people were vested with trustworthy knowledge because they have socio-cultural experiences, seen things, sufferings, including climate events, changes, and impact. Broadly, the local traditions and practices stranded in systems of meanings and relationships visualized on experiences, cultural models and bizarre ritual reconciling farmers involvement with natural phenomena and processes, has been structuring the ways they observed, understood, experienced, and responded to key elements of the world they are living. The farmers, through their indigenous knowledge systems embedded with updated integrated versions have developed and implemented extensive adaptation strategies that have enabled them reduce vulnerability to climate variability over the years. However, this knowledge has been rarely taken into consideration by policy makers in the design and implementation of modern mitigation and adaptation strategies on climate change impact on agriculture.

\section{Conclusion}

Compared to the farmers of developed regions and countries, the rural farmers of Nepal Terai are being affected more by climate change impact due to their low capacity to cope with and to adapt. Excessive dependence on natural resources, subsistence agricultural production, deforestation and extension of new settlement made Jamuni farmers more vulnerable to sinful problem of climate change impacts that impinged on their interactions with environment not only through its impact on biodiversity, agricultural practices and livelihood wellbeing, but also as a dimension of collective narratives and the uncertainties for future.

The locally fashioned performative integrated adaptation practices ingrained in environmental anthropology of the broad inter-relationship between culture and ecology mediated the engagements with natural phenomena and processes and framed the way farmers observed, understood, experienced, and adapted to climatic variations with a set of responses in crop selection, livestock management and livelihood. Farmers as innovators, creative technical actors and as socio-cultural actors responding in environmental circumstances adjusted their adaptation behaviors within the complications of agrarian socioecological systems that portray how adaptive agricultural performance is embedded within socio-cultural performance intertwined with social-cultural, technical and ecological contexts, hence proving that climatic adaptation is noticeably a socio-cultural process. It also verify that climatic adaptation is a go-ahead process that is socioculturally embedded, a set of modeled responses to the conditions and adaptive processes as socio-cultural-technical phenomena best for community solidarity and collectivism. But with financial constraints and poor knowledge on modern adaptation techniques of climate change, adaptation mechanisms were insufficient, compelling many farmers to shift from agriculture to foreign labor, hence increasing future threat of food security with declining agro-production.

As effective adaptation not only needs to be technically effective in reference to climate and ecology, but needs to be effective in reference 
to the socio-cultural needs of the individuals and collectivities that perform them, at the policy level, it is requisite recognizing time and space bound locally suitable adaptation experience model shaped into integrated knowledge based performative practices in climate change policies to develop cost-effective, participatory, sustainable and effective adaptation strategies on agriculture and livelihood. However, there are challenges not only owing to the human dimensions of climate change, but because of the ideological and socio-cultural nature of climate science and its probable significant role in policy decisions that affect the lives of local farmers.

\section{References}

1. Government of Nepal, Ministry of Environment. National Adaptation Programme of Action (NAPA) to Climate Change. Singha Durbar, Kathmandu, Nepal; 2010.

2. Kates RW. Cautionary tales: adaptation and the global poor. Climatic change. 2000;45(1):5-17.

3. Aase TH, Chaudhary RP, Vetaas OR. Farming flexibility and food security under climatic uncertainty: Manang, Nepal Himalaya. Area. 2010;42(2):228-238.

4. Intergovernmental Panel on Climate Change (IPCC). Climate Change 2007: Impacts, Adaptation and Vulnerability. Cambridge: Cambridge University Press; 2007.

5. Manandhar S, Vogt DS, Perret SR, Kazama F. Adapting cropping systems to climate change in Nepal: a cross-regional study of farmers' perception and practices. Regional Environmental Change. 2011;11(2):335-348.

6. Alternative Energy Promotion Centre (AEPC). District Climate and Energy Plan Bardiya District. Lalitpur, Nepal: National Rural \& Renewable Energy Programme; 2014.

7. Local Administrative Units Map and Wards in Bardiya. District Development Profile (DDP) of Bardiya (2017).

8. Chhetri RB. Adaptation of Tibetan refugees in Pokhara, Nepal: A study on persistence and change. 1992.

9. Eisenack K, Stecker R. A framework for analyzing climate change adaptations as actions. Mitigation and Adaptation Strategies for Global Change. 2012;17(3):243-260.
10. White LA. The Evolution of Culture: The Development of Civilization to the Fall of Rome. Routledge; 2016.

11. Cook J. Positives and negatives of global warming. Skeptical Science.

12. Aryal SP, Pokharel BK. Nepal's Climate Change Policies and Plans: Local Communities' Perspective, Environment and Climate Series 2011/1. HELVETAS. 2011.

13. Pelling M. Adaptation to climate change: from resilience to transformation Routledge. Oxon, UK. 2011.

14. Ajani EN, Mgbenka RN, Okeke MN. Use of indigenous knowledge as a strategy for climate change adaptation among farmers in sub-Saharan Africa: implications for policy. 2013.

15. Karki M, Adhikari JR. Integrating indigenous, local and modern knowledge for sustainable conservation and management of forest ecosystems in Nepal. Forestry Nepal: Gateway to Forestry Information in Nepal. 2015.

16. Richards P. Cultivation: Knowledge or Performance?. An Anthropological Critique of Development: The Growth of Ignorance. M. Hobart. London, Routledge; 1993.

17. Ajibade LT, Shokemi OO. Indigenous approach to weather forecasting in ASA LGA, Kwara State, Nigeria. Indilinga African Journal of Indigenous Knowledge Systems. 2003;2(1):37-44.

18. Pennesi K. The predicament of prediction: Rain prophets and meteorologists in northeast Brazil. 2007.

19. Orlove BS, Chiang JC, Cane MA. Ethnoclimatology in the Andes: a crossdisciplinary study uncovers a scientific basis for the scheme Andean potato farmers traditionally use to predict the coming rains. American Scientist. 2002;90(5):428-435

20. Nabhan GP. The Desert Smells like Rain: A Naturalist in O'odham Country. University of Arizona Press; 2002.

21. Orlove B, Roncoli C, Kabugo M, Majugu A. Indigenous climate knowledge in southern Uganda: the multiple components of a dynamic regional system. Climatic Change. 2010;100(2):243-265.

22. Tschakert P. Views from the vulnerable: understanding climatic and other stressors in the Sahel. Global Environmental Change. 2007;17(3-4):381396.

23. Strauss S, Orlove B. Up in the air: the anthropology of weather and climate. In: Weather, Climate and Culture. Oxford: Berg Publishers; 2003:3-14. 